\title{
STRUCTURE ISOLATION IN ORDER TO REDUCE VIBRATION TRANSFER FROM THE SUBSOIL
}

\author{
D. MAKOVIČKKA ${ }^{1} \&$ D. MAKOVIČKA ${ }^{2}$ \\ ${ }^{1}$ Klokner Institute, Czech Technical University in Prague, Czech Republic. \\ ${ }^{2}$ Static and Dynamic Consulting, Czech Republic.
}

\begin{abstract}
Vibrations caused by road or railway vehicles running on surface or underground roads or rail tracks spread through the subsoil into surrounding building structures. These vibrations usually pose no threat to the safety of the structures, but they may limit the use of devices sensitive to vibrations in the buildings. An elastic foundation for the whole structure on a compliant rubber layer inserted into the foundation structure is a solution that restricts the transfer of vibrations into the buildings. The reinforced concrete structure of a building is used as an example here to illustrate the efficiency of using a rubber layer in the footing bottom in order to reduce the propagation of vibrations into the building below the level observed in a non-isolated building structure when loaded by vibrations induced by traffic.
\end{abstract}

Keywords: Building structure, dynamic response, traffic vibration, vibro-base isolation.

\section{INTRODUCTION}

Vibrations propagate into the surroundings of the traffic line through the geological environment and act as technical seismicity, which loads the buildings in the vicinity. The histories of measured vibrations were used as loads applied to a modelled building structure at the foundation base.

This article discusses ways of implementing vibration isolation in the foundation structure of a building in order to reduce the flow of vibrations into the protected part of the structure. For this model, the predicted vibrations in the individual storeys were shown and were compared with the level of excitation vibrations on the foundation base.

The dynamic effects of subsurface traffic propagating through the ground environment into the ambient buildings of urban agglomerations have been acquiring ever increasing importance. Construction firms try to use the areas in the proximity of underground lines because of their lucrative location, usually for residential construction. It is these structures erected in the proximity of underground tunnels or directly above them in the case of shallow tunnels that are threatened by vibrations from underground traffic. These vibrations propagate as non-stationary vibrations to the foundations of buildings in the vicinity of their source.

The nature and magnitude of the vibrations caused by technical seismicity [1-4] depend not only on the proximity and the nature of the source of the vibrations but also on the local geological conditions and on the structure of the affected building. Due to its tuning, the building structure usually amplifies or, in better cases, reduces the effects of technical seismicity.

Vibro-base isolation is an effective method for reducing the vibration level of the protected structure as a whole with reference to its foundation types (plate, piles, strips, etc.) [1, 5-9]. Base isolation is one of the most powerful passive structural vibration control technologies in earthquake engineering. It is meant to enable a building or some other structure to survive a potentially devastating seismic (or in our case technical seismic) impact through suitable initial design or subsequent modifications. In some cases, the application of base isolation can considerably raise both the seismic performance and the lifetime of a structure. 
The base isolation system consists of isolation units or isolation layers, where:

a. Isolation block units are the basic elements of the base isolation system which are intended to provide the decoupling effect for a building or a non-building structure $[1,6,7,9]$.

b. Isolation slab units are plate elements from which the isolation layer is composed $[3,10]$.

The principle of vibro-isolation (case b) in the footing bottom is implemented by inserting a flexible layer of rubber or some other elastomer between the double foundation slabs. This elastic layer must be protected against flooding due to precipitation or underground water.

Elastic elements of rubber and other similar materials can be used for this vibro-base isolation. In Czech conditions, rubber layers are currently applied in several structures as full-area vibro-base isolation. These elastic elements are usually placed at foundation bottom plate level or on the foundation slab or strips, while the upper part (plate) of the foundation structure is situated on top of these isolated elements by means of sufficiently wide footings. The principle involves consistent separation of the upper part of the structure from the lower part of the foundation structure and the subsoil by this elastic layer. The thickness of this continuous elastic layer, or of blocks of several strata of this material, and their distribution, must be determined from the mechanical properties of the rubber (particularly its stiffness) and its static prestress on the basis of a static and dynamic analysis of the whole building.

A disadvantage of this solution is that the rubber elements are usually inaccessible during the service life of the structure and, consequently, it is difficult or impossible to replace them. Another disadvantage concerns changes in the properties of rubber due to ageing, influenced particularly by sunshine and the presence of petrol or petroleum derivatives. However, the advantage of rubber layers is that they provide sufficient damping to reduce the resonance peaks of vibrations of the elastic-supported structure.

Vibrations produced by traffic sources usually do not threaten the safety of structures, but their undesirable impacts can significantly lower the quality of life and the working conditions of people living or working in residential or office parts of the building. Vibrations of this type usually exceed the safety limits determined by hygiene standards for building occupants and service standards of equipment that is housed, long before any [11] failures and cracks appear in the structure.

An example of a reinforced concrete skeleton structure of a building is used to illustrate the efficiency of vibro-base isolation performed in the footing bottom for various compositions of the vibro-isolation layer. The efficiency of the isolation was evaluated according to the vibration level of storeys in a building constructed without vibro-isolation, and, alternatively, in the same structure with a flexible rubber layer inserted, for vibrations excited by the operation of underground trains in the conditions in Prague.

\section{VIBRATION LOAD}

The dynamic effects of traffic vibrations propagating through the ground environment into the ambient buildings of urban agglomerations have been acquiring ever increasing importance. Construction firms make efforts to exploit areas in the proximity of underground lines because of their lucrative location, usually for residential construction. In the proximity of underground tunnels or directly above shallow tunnels, they erect structures that are threatened by vibrations from underground traffic.

The amplitude level of the exciting vibrations and their frequency composition must be known in order to perform a dynamic analysis of the building structure $[1,7,12,13]$. In order 
to determine the dynamic response of the structure, it is advisable to use the time course of the vibrations (Figs 1 and 2) measured on the level of the footing bottom of the building or in the close vicinity on the underground structure or on the foundation of neighbouring buildings.

Figures 1a and 2a show the measured time course of the vibrations in an underground station structure in the conditions of Prague, on a more recently constructed part of the B line route, during the passage of one entire underground train [7]. Figures $1 b$ and $2 b$ indicate the selected intervals of the measured values of the time functions of the load, which contain the dominant vibration components. In this measured case, the building structure should be separated from the underground structure only by a dilatation joint. The measured time history of excitation at the platform of a train station was, therefore, used for structural analysis.
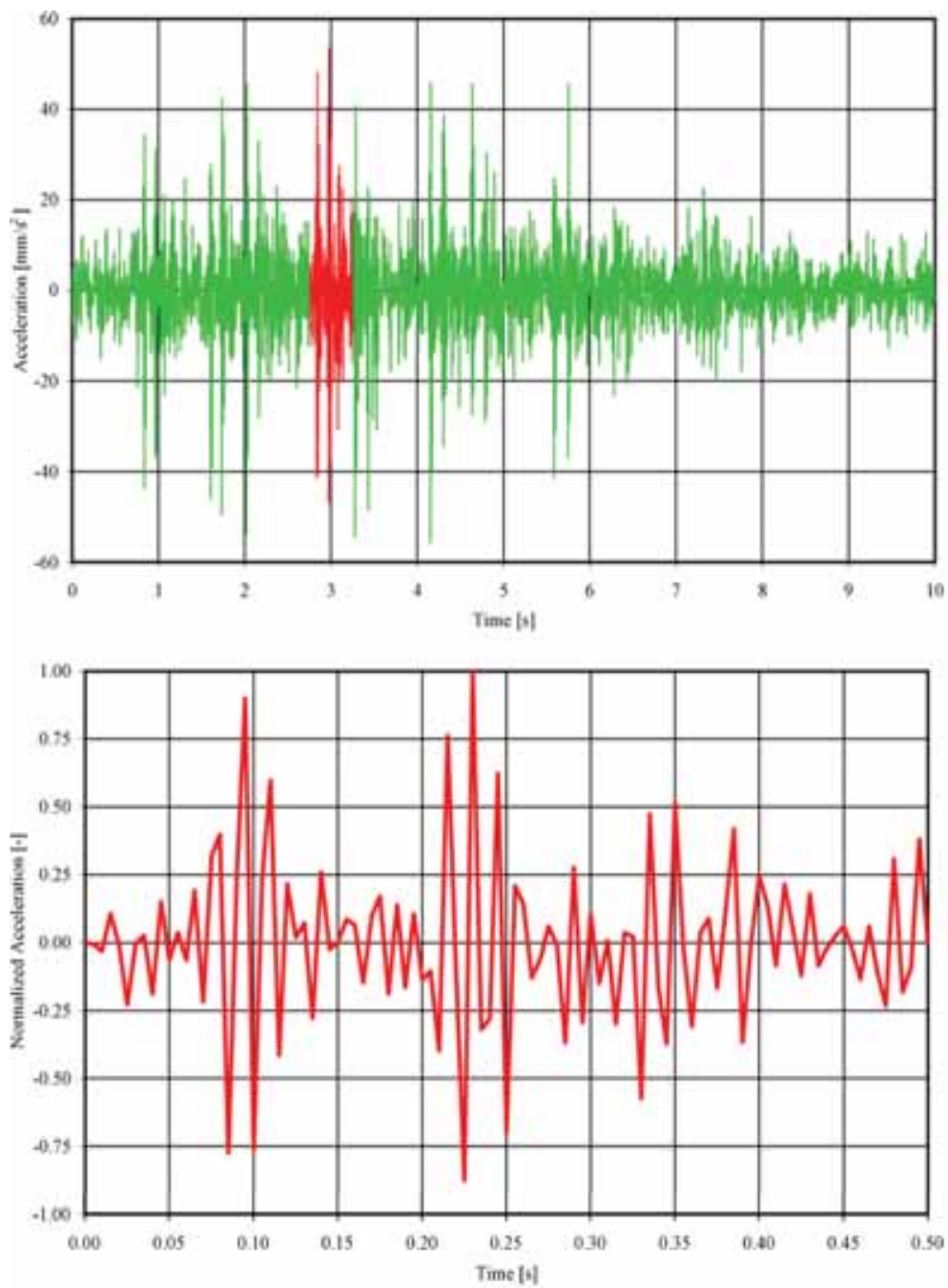

Figure 1: Measured vertical vibrations caused by the operation of an underground train. The whole passage of the train (a, above) and the part of the excitation used here (b, below). 

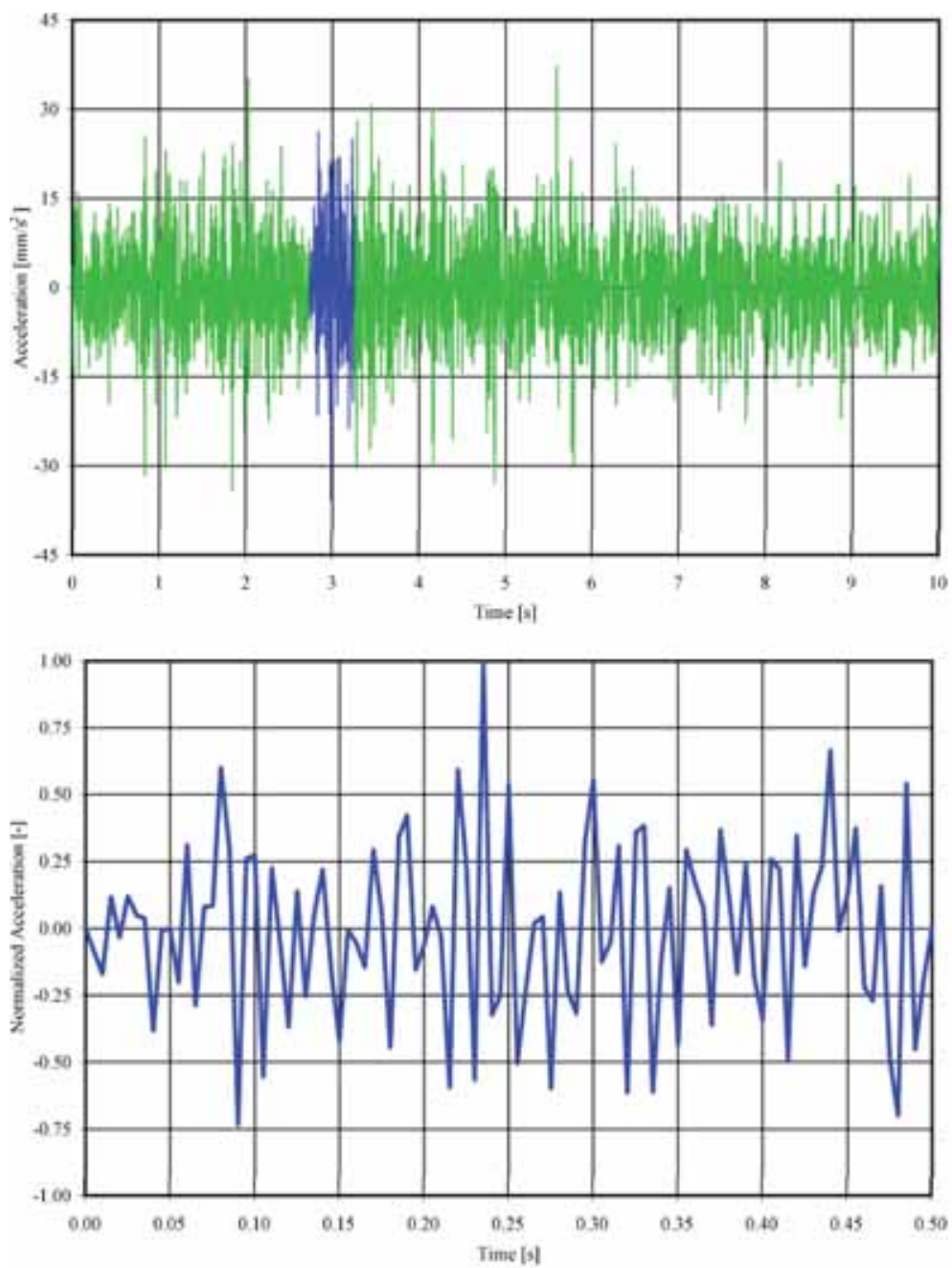

Figure 2: Measured horizontal vibrations caused by the operation of an underground train. The whole passage of the train (a, above) and the part of the excitation used here (b, below).

The analysed building was not under construction during the measurements in the design stage (and the base level was not accessible).

When planning the correct measures for a structure that we intend to protect against excessive vibrations, we therefore need to know the amplitude level and the frequency content of the vibrations which will propagate from the underground into the building. However, the measured real characteristics of the vibrations on the underground platform may show considerable mutual differences (Fig. 3), because the magnitude of the vibrations $\left(a_{\mathrm{ef}}\right)$ depends on the general parameters of the train, the driving style, the structures of the stations and tunnels, etc. The maximum measured history of a train pass (see Fig. 2) was used for building excitation (Fig. 1b) in the vertical direction. The same procedure was used for the horizontal direction. The examination of the measured FFT spectra shows the dominant frequency 


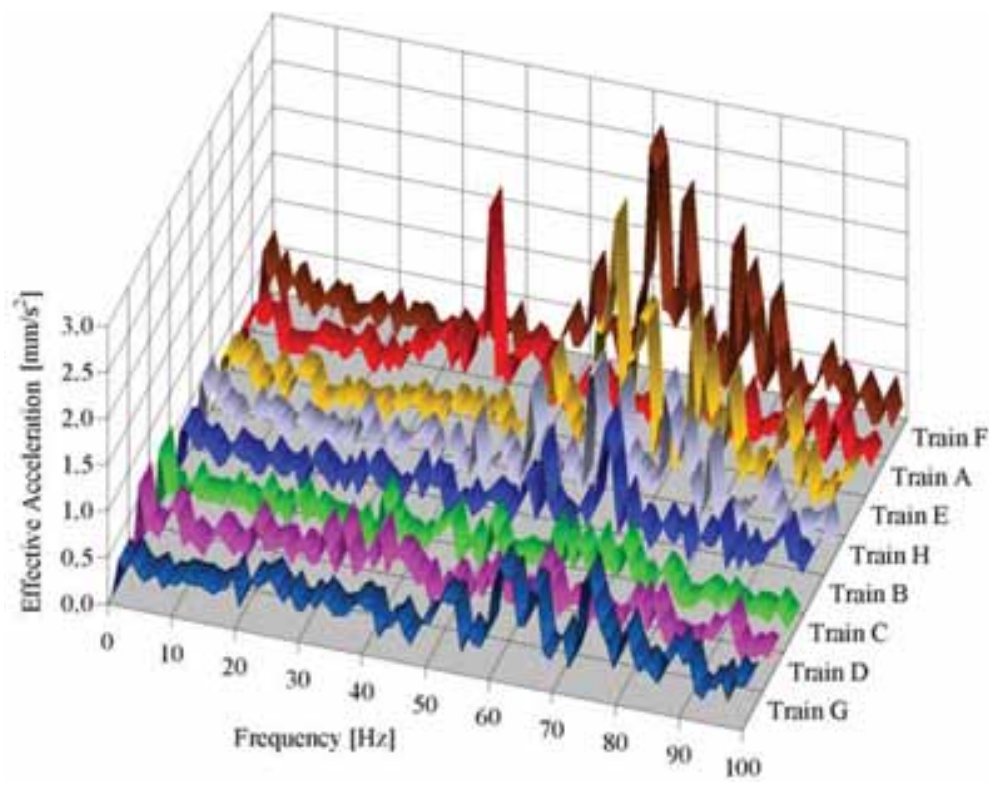

Figure 3: FFT spectra of vertical vibration as trains pass.

interval of this excitation (about $40 \mathrm{~Hz}$ and between 55 and $80 \mathrm{~Hz}$ ) and the variability of the quantity of frequency components in this range.

It is helpful to use the time course of the vibrations in the form of vibration acceleration values because, in order to perform the dynamic calculation, computational programs usually require that the acting dynamic load be entered as the time course of the forces in terms of acceleration at individual points of the structure, in our case the foundation slab. Since the time courses of the acceleration histories of the two considered vibrations, in a vertical direction and in a horizontal direction, correspond to the time courses of the dynamic force loads, the normalized time courses of the acceleration can be used as time functions of the course of the force load.

In the computational model, the dynamic load is introduced on the level of flexible pointbased supports of the structure, located equidistantly on the foundation structure. This means that the losses in the transfer of vibrations at the contact place between the subsoil and the foundation structure are neglected. This is a safe assumption, and it also increases the conservative nature of the solution.

\section{COMPUTATIONAL MODEL OF THE STRUCTURE}

A typical reinforced concrete monolithic structure (Fig. 4) was chosen for a dynamic analysis, with the reinforced concrete core, and with the staircase and lift part made of concrete class C25/30. The ground-plan dimensions of the each storey are $12 \times 18 \mathrm{~m}^{2}$. The structural height of a storey is $3 \mathrm{~m}$; the building has one underground storey and eight above-ground storeys.

The ceiling slabs as well as the roof slab are $150 \mathrm{~mm}$ in thickness. The foundation slab is designed as divided for the purpose of inserting the vibro-isolation; both the bottom foundation slab and the upper foundation slab are $500 \mathrm{~mm}$ in thickness. The columns on each storey are square-shaped, $300 \times 300 \mathrm{~mm}^{2}$, in the $6 \times 6 \mathrm{~m}^{2}$ module. The circumferential reinforced 

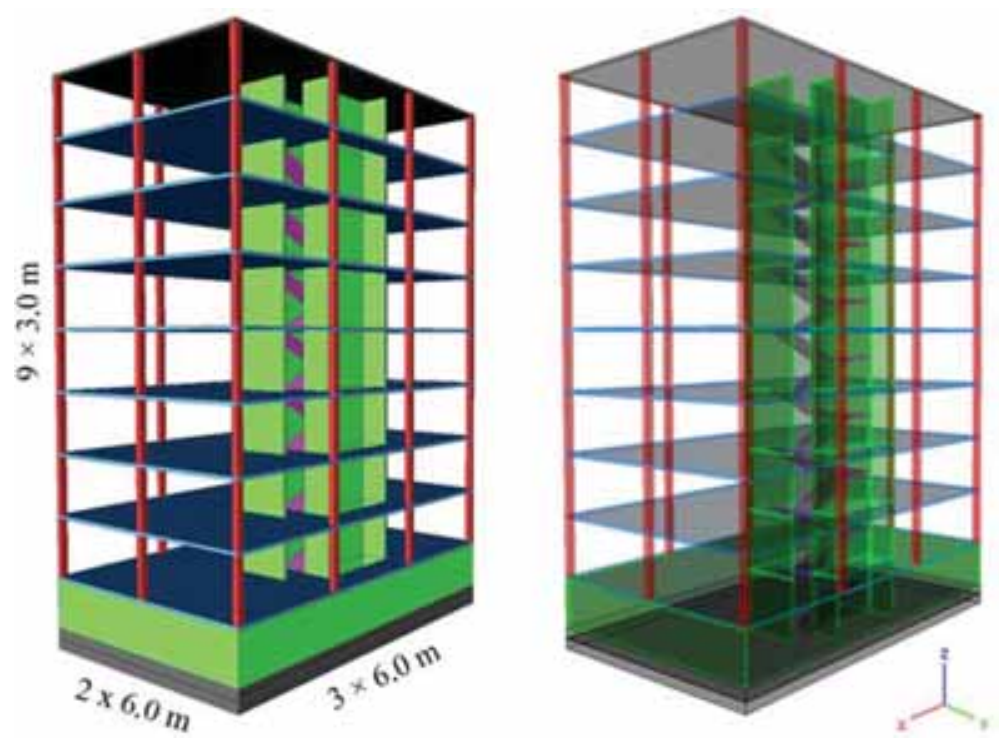

Figure 4: Computational model of the building structure, solid and transparent view.

concrete walls on the underground storey, and also the lift and staircase walls, are $200 \mathrm{~mm}$ in thickness.

The circumferential skin of the storeys above the ground is considered as having $150 \mathrm{~kg} / \mathrm{m}^{2}$ mass. The foundation slab of the building is supported by piles. The piles are distributed in the $6 \times 6 \mathrm{~m}^{2}$ module. The vertical strength of one pile is $16 \mathrm{GN} / \mathrm{m}$.

Isolation plates $500 \times 500 \mathrm{~mm}^{2}$ in cross-section and $30 \mathrm{~mm}$ in height, composed of extruded rubber, were used for vibro-isolation of the structure. This rubber layer was inserted between the bottom and upper parts of the foundation slab - the rubber distribution is shown in Fig. 5.

The rubber layer must be protected against water using two-sided hydro-isolation (from above and from below), using a geotextile against damage during assembly of the reinforcement together with concreting of the upper part of the foundation slab. Vertical vibro-base isolation of the circumferential reinforced concrete walls below the terrain level was performed similarly. Part of the construction of this horizontal isolation layer is shown in Fig. 6.

The modulus of elasticity and the strength of the compressed rubber were determined by tests in the laboratory, using rubber samples of the same dimensions as those inserted in the structure. The stress-stress curve shows a non-linear course depending on the compression rate of the rubber. Its modulus of elasticity was then introduced into the computational model according to the static compression of the rubber. At the (pile) support points, a modulus of elasticity value $E=2.78 \mathrm{MPa}$ was used; and in the fields among the supports a modulus of elasticity value $E=1.62 \mathrm{MPa}$ was applied.

For a comparison with the response characteristics of the isolated and non-isolated building, the same building model was used, but for the non-isolated building a rigid connection between the upper and lower parts of the foundation slab was considered.

Linear elastic behaviour of the structure loaded by non-stationary dynamic excitation caused by the operation of an underground train was assumed. 


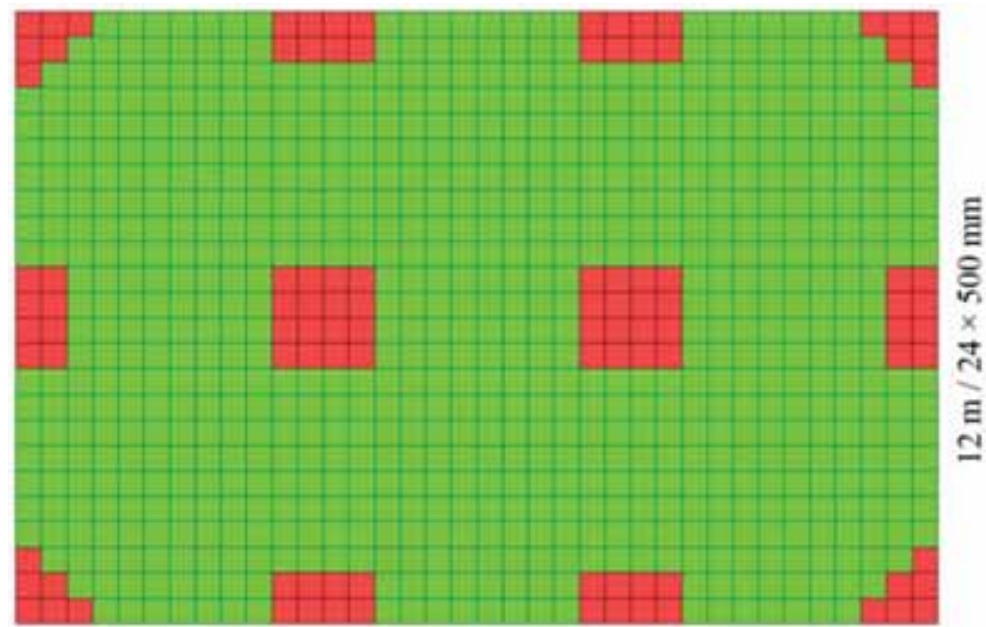

$18 \mathrm{~m} / 36 \times 500 \mathrm{~mm}$

Rubber A: $\mathrm{E}=2.78 \mathrm{MPa} \quad$ Rubber $\mathrm{B}: \mathrm{E}=1.62 \mathrm{MPa}$

Figure 5: Rubber layout.

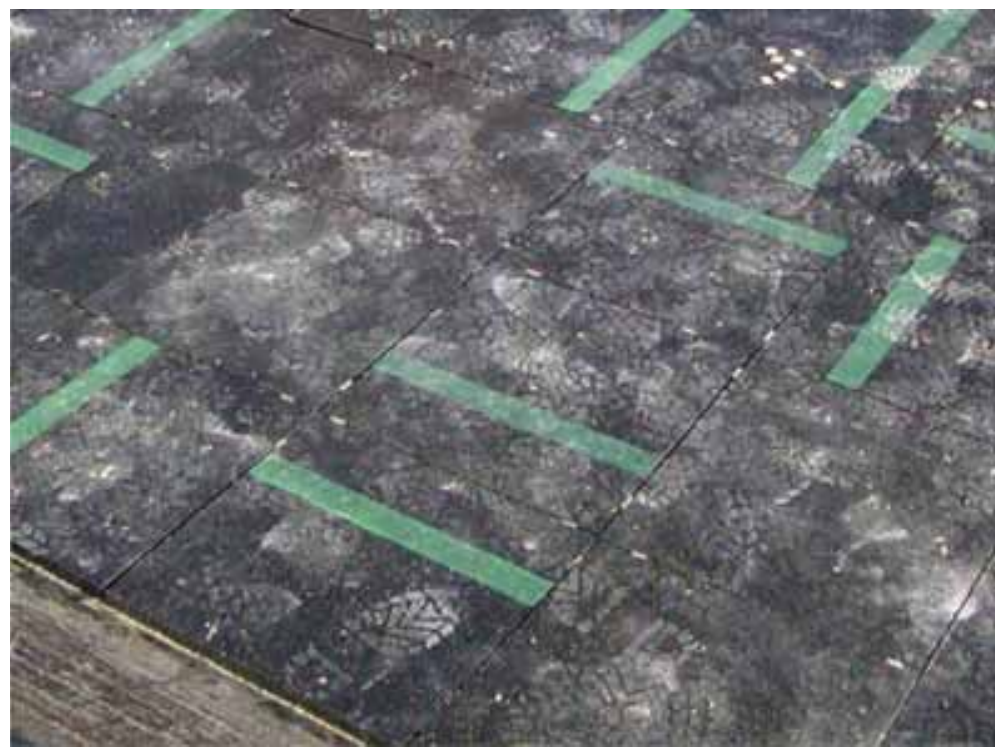

Figure 6: Construction of the rubber isolation layer.

\section{DYNAMIC ANALYSIS}

A numerical model of the building (Fig. 4), together with the layout of the rubber distribution in the foundation part (Fig. 5), takes into account the individual storeys, broken down into the floor, the foundation and the roof slabs, the columns, the load-bearing walls and the peripheral and interior girders. The building is situated above and in the close vicinity of an 
underground route. The ground-plan dimensions of the building and of the underground structure were similar, and they were in close proximity, so a simplified assumption was adopted that the measured vibrations, usable for excitation, act with the same intensity and with no phase delay beneath the whole building. The excitation was applied from below onto the lower foundation slab at the place where the piles are attached, as variants for vertical and horizontal excitation. The difference in the intensities and frequencies of the time histories between vertical and horizontal excitation was used for excitation (compare Figs 1 and 2). The methodology for the computational analyses for the two directions of excitation was unchanged.

\subsection{Natural vibrations}

The dynamic analysis was performed using the Scia Engineer computational code [14]. The 3D computational model of the structure corresponds to the dimensions of the structure, including its mass. The mass corresponding to the permanent component of the live load was included in the mass of the ceiling slabs (estimated at $50 \%$ of the live load). The circumferential facade skin and the roof attic $1 \mathrm{~m}$ in height were included in the structure model as the line load, and as the appropriate mass along the circumference of the ceiling slabs.

The tuning of the structure corresponds to the calculated natural frequencies and natural modes. The most significant natural frequencies of the structure with and without vibroisolation are included in Table 1. The first six natural modes are also shown in Fig. 7.

Table 1: Natural modes and frequencies for an isolated structure versus a non-isolated structure.

Natural frequency $(\mathrm{Hz})$

\begin{tabular}{cccl}
$\begin{array}{c}\text { Natural frequency }(\mathrm{Hz}) \\
\begin{array}{c}\text { Without } \\
\text { vibro-isolation }\end{array}\end{array}$ & $\begin{array}{c}\text { With } \\
\text { vibro-isolation }\end{array}$ & Figure 6 & Character of natural mode \\
\hline 1.22 & 1.03 & $f_{(1)}$ & $\begin{array}{l}\text { Torsion of the whole building round the } \\
z \text { axis }\end{array}$ \\
1.70 & 1.42 & $f_{(2)}$ & $\begin{array}{l}\text { Torsional-translational motion round the } z \\
\text { axis and in direction } y\end{array}$ \\
1.98 & 1.49 & $f_{(3)}$ & $\begin{array}{l}\text { Torsional-translational motion round the } z \\
\text { axis and in direction } x\end{array}$ \\
4.52 & 4.32 & $f_{(4)}$ & $\begin{array}{l}\text { Torsion round the } z \text { axis and floor slab } \\
\text { bending }\end{array}$ \\
6.29 & 5.44 & $f_{(5)}$ & Higher modes of floor slab bending \\
6.34 & 5.74 & $f_{(6)}$ & \\
6.91 & 6.14 & - & \\
6.98 & 6.52 & - & \\
6.99 & 6.82 & - & \\
7.03 & 6.91 & - &
\end{tabular}



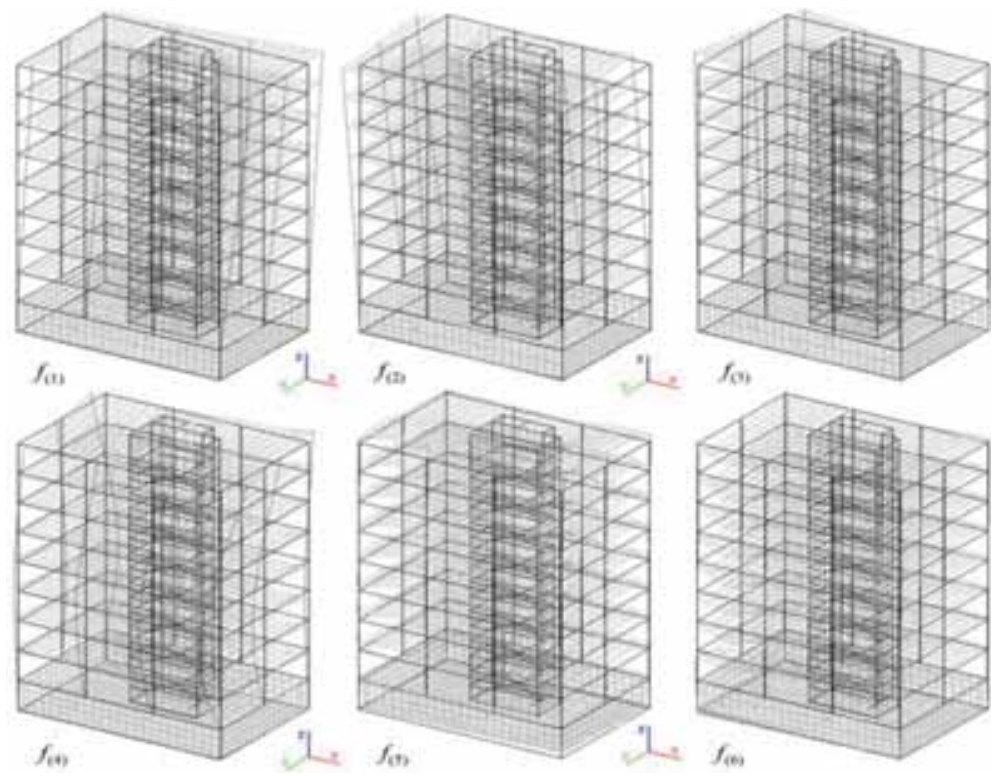

Figure 7: The first six natural modes of vibration.

For the dynamic response to the effects of external actions (traffic), the lowest possible tuning of the rubber-mounted structure is decisive. This manifests itself, on the one hand, through flexural vibrations of the vibro-based building in the environs of $1 \mathrm{~Hz}$, and, on the other hand, by vertical and horizontal sliding vibrations of the building as a whole, or by torsion vibrations.

Not only do the basic natural vibration modes appear in the computation but also the higher natural vibration frequencies of the individual storeys, and in some cases the columns and walls, balconies, etc., which makes the response of the building on each storey slightly different (higher, lower, possibly with antinodes on different sites).

\subsection{Forced vibration}

A dynamic analysis was performed using the method of dynamic load decomposition into 50 natural modes of structural vibration. The value of $3 \%$ as the modal damping ratio was considered for all the modes. The use of different damping ratio values for the natural modes used here is not supported by the calculation code. The response of the structure was calculated using a time step of $0.005 \mathrm{~s}$.

This rubber vibro-isolation layer was inserted between the bottom and upper foundation slabs. The rubber plate components $500 \times 500 \times 30 \mathrm{~mm}^{3}$ in size were modelled in the numerical analysis as one-sided hinged beam elements with a cross-section of $500 \times 500 \mathrm{~mm}^{2}$ and a length of $30 \mathrm{~mm}$. The dynamic load as a force action was introduced on the level of the bottom slab in the nodes of regular mesh, given by supporting piles and rubber beam elements, and stepwise in the vertical and horizontal directions.

To determine the vibration transfer from the bed to each storey of the structure, the response was calculated repeatedly so that the maximum vibration displacement of the vibration on the level of the lower foundation slab would be equal to a dimensionless value 1 at the point of 
highest vibration. Thus, the displacements on the upper foundation slab and on the floor slabs of the higher storeys are also dimensionless.

The peak values for the displacements of each storey were evaluated from the calculated structure response, and these values were used to determine the envelopes of the maximum vibration values for each storey (for selected storeys, the maximum envelope values of the vibrations are shown in Fig. 8), and for each excitation direction for the variants of an isolated and a non-isolated structure.

Figure 8 clearly indicates the efficiency of the vibro-isolation and, on the other hand, the amplification of the vibrations on higher storeys for the non-isolated structure, which is caused by the tuning of the structure.

The time course of the vibrations at selected points on each storey is shown in Fig. 9, calculated for points on the vertical line passing in the vicinity of the southwest corner of the building.

It follows from the calculated time courses of the vibration that an excitation introduced into the structure due to traffic vibration is felt as a significant vibration, particularly on the lowest storey. The most intensively vibrating points are found near the piles and in
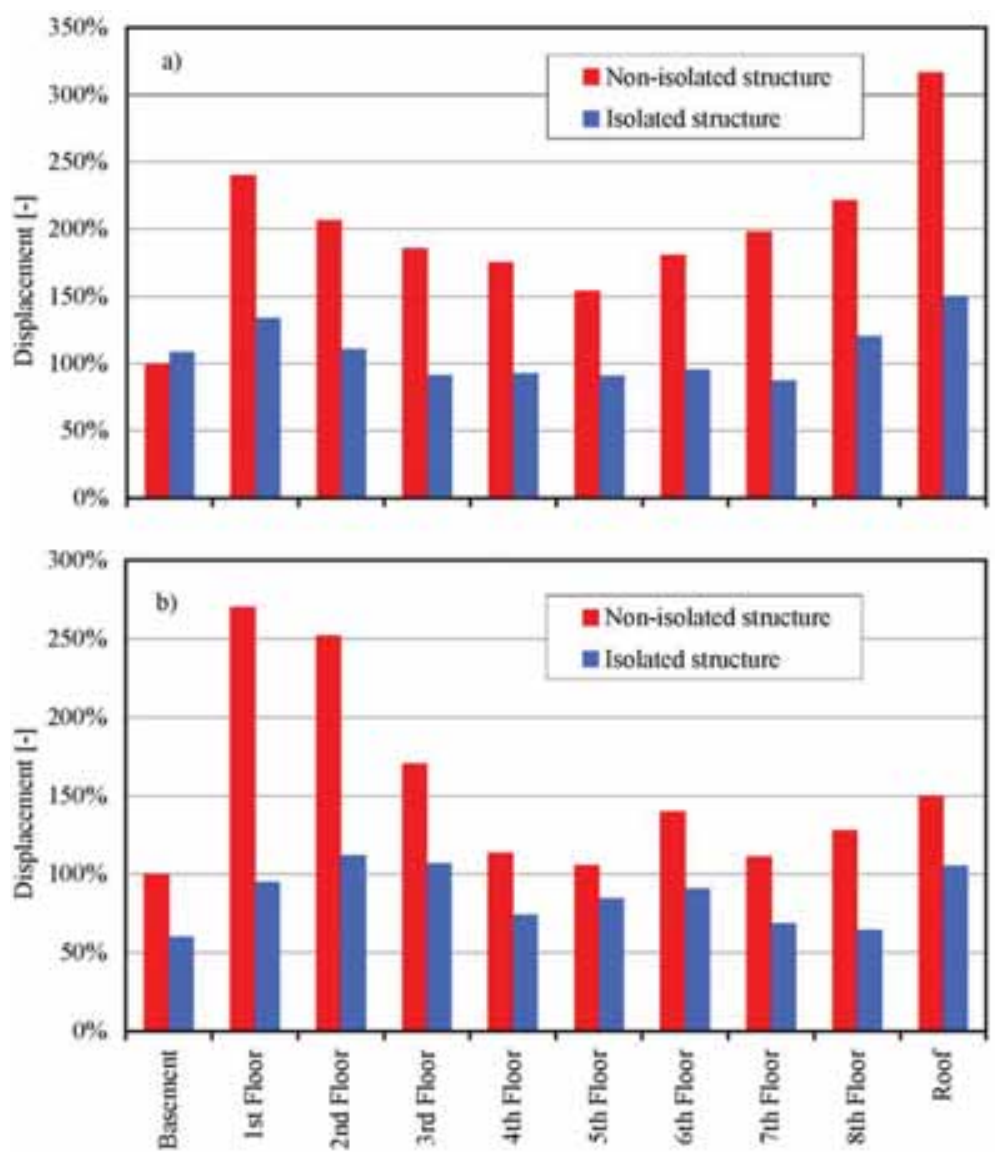

Figure 8: Peak displacement values for each floor slab: (a) vertical and (b) horizontal excitation. 

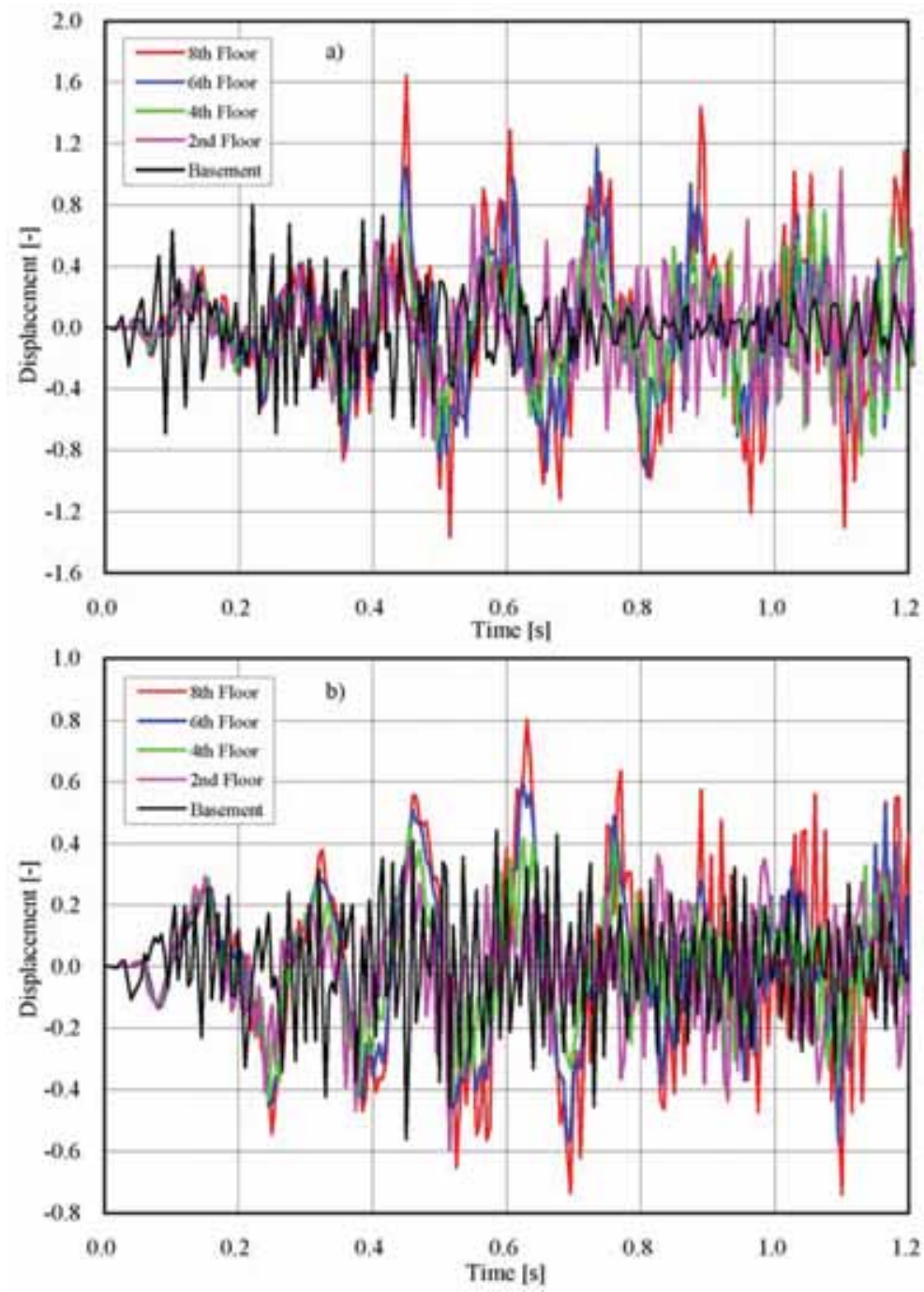

Figure 9: Time history of the relative vertical displacements under vertical excitation: (a) nonisolated structure and (b) isolated structure.

parts of the structure that are spatially situated toward the side of the railway. With increasing height of the building, the dynamic response on particular floor levels decreases in cases where the mass and stiffness of the higher storeys are comparable. This effect manifests mainly on the lowest natural vibration modes, because the inertia of a substantial part of structure is relatively high, and the compliance of the building parts at lower frequencies is low. For a non-isolated structure, this phenomenon is similar but the dynamic excitation is at higher frequencies, and is not reduced through the vibro-isolation effect. The differences in response between isolated and non-isolated structures are more marked on the higher storeys. 


\section{CONCLUSION}

This paper has dealt with the application of an elastic anti-vibration layer at foundation base level in order to eliminate excessive traffic vibrations from an underground railway structure propagating to the assessed building through the geological environment. When a train is in motion, the dominant vibrations are transferred to the environments in the form of nonstationary vibrations produced by the motion of the train across the interface of the different types of underground tunnel structures (in our case).

The computed vibration histories of the examined building reveal that the vibrations of the isolated structure are decreased in all the above-ground storeys. The effectiveness of the vibro-isolation is determined by the frequency tuning of the isolated structure. The lower the tuning of the structure based on elastic vibro-isolation (the lower the dominant natural frequencies), the greater the decrease in the higher vibration frequencies propagating into the structure from its geological environment. In the case of a rigid foundation of the building, on piles or on a foundation plate without isolation, the vibrations would propagate from the subsoil directly into the RC building structure, practically without decreasing.

In most cases, the major influence of this traffic vibration is limited to the lowest two or three storeys. In the higher storeys, the time characteristic of the vibrations is divided into lower natural frequencies. Other elements reducing the vibration level in the individual storeys are non-load-bearing partitions, floating floors, carpets on floors, etc. However, an analysis of these factors is beyond the scope of this paper. The floor acceleration response for each storey should be estimated in such a case, as it is the most important response parameter for the issues that are addressed in this paper (comfort of residents, protection of contents and equipment of the building).

The application of vibro-isolation is, consequently, a very efficient way to reduce the transfer of vibration from the subsoil to the interior parts of the building.

\section{ACKNOWLEDGEMENT}

This research was supported as a part of the research projects within the framework of GAČR P105/11/1580 (Transient response of structure under short-term dynamic or impact load due to seismic effects and explosions), for which the authors would like to thank the Agency.

\section{REFERENCES}

[1] Jacquet, T. \& Heiland, D. Tieffrequente Bauwerken-Kopplungen als Schutz gegen Erschütterungen, Gerb: Berlin, 2002.

[2] Makovička, D. \& Makovička, D., Jr., Response analysis and vibroinsulation of buildings subject to technical seismicity. Earthquake Resistant Engineering Structures VII, WIT Press: Southampton, UK, pp. 197-205, 2009. doi: http://dx.doi.org/10.2495/ ERES090181

[3] Makovička, D. \& Makovička, D., Jr., Springing of building structure in order to eliminate traffic vibrations, EURODYN 2011: Proceedings of the 8th International Conference on Structural Dynamics, Leuven, pp. 922-927, 2011.

[4] Hunaidi, O., Traffic Vibrations in Buildings, National Research Council of Canada, No. 39, June 2000.

[5] Giame, J., Saha, P., Shoemaker, D. \& Sievers, L., A passive vibration isolation stack for LIGO: design, modeling, and testing. Review of Scientific Instruments, 67(1), pp. 208-214, 1996. doi: http://dx.doi.org/10.1063/1.1146573 
[6] Kay, H., Nachträgliche Schwingungsisolierungen von Gebäuden. Spezialtiefbau, TIS(4), pp. 14-18, 2001.

[7] Komodromos, P., Seismic isolation for earthquake resistant structures. Advances in Earthquake Engineering Series, WIT Press: Southampton, UK, 2000.

[8] Makovička, D. \& Makovička, D., Jr., Dynamic response of a building with vibrobase insulation. IV. European Conference on Computational Mechanics, May 16-21, Paris, France, pp. 1367-1368, 2010.

[9] Phocas, M.C., \& Pamboris, G., Multi-storey structures with compound seismic isolation. Earthquake Resistant Engineering Structures VII, WIT Press: Southampton, UK, pp. 207-216, 2009. doi: http://dx.doi.org/10.2495/ERES090191

[10] Makovička, D. \& Makovička, D., Jr., Effect of vibro-insulation on restriction of vibration transfer from subsoil into the building. Engineering Mechanics 2011, 17th International Conference, Institute of Thermomechanics, Academy of Sciences of the Czech Republic, v.v.i. Brno, pp. 375-378, 2011.

[11] ISO 2631-2:1989, Evaluation of human exposure to whole-body vibration - Part 2: Continuous and shock-induced vibration in buildings (1 to $80 \mathrm{~Hz}$ ).

[12] Makovička, D. \& Makovička, D., Jr., Determination of seismic transport effects on buildings. Earthquake Resistant Engineering Structures VI, WIT Press: Southampton, UK, pp. 353-362, 2007. doi: http://dx.doi.org/10.2495/ERES070341

[13] Makovička, D. \& Makovička, D., Jr., Vibrobase insulation of a building excited by the technical seismicity effect of tube railway operation. Earthquake Resistant Engineering Structures VIII, WIT Press: Southampton, UK, pp. 79-88, 2011.

[14] Scia Engineer, release 2011, No. of version 11.0.1172, SCIA Group NV, Herk-de-Stat, Belgium, 2012. 